\title{
"Building" the Twenty-First Century Child and Adolescent Psychiatrist
}

\author{
Deepika Shaligram ${ }^{1}$ (D) Bettina Bernstein ${ }^{2} \cdot$ Sandra M. DeJong $^{3} \cdot$ Anthony P.S. Guerrero $^{4} \cdot$ Jeffrey Hunt ${ }^{5}$. \\ Mandar Jadhav ${ }^{6}$. Say How Ong ${ }^{7} \cdot$ Paul Robertson $^{8} \cdot$ Asilay Seker $^{9} \cdot$ Norbert Skokauskas $^{10}$
}

Received: 14 August 2021 / Accepted: 18 January 2022 / Published online: 4 February 2022

(C) Academic Psychiatry 2022

About $20 \%$ of children in the United States (US) have a diagnosed mental health disorder; half of them did not receive treatment from a mental health professional pre-pandemic [1]. The COVID-19 pandemic has exacerbated pre-existing mental health burden and healthcare disparities [2]. Improving pediatric mental health outcomes positively impacts educational and judicial systems, family functioning, and future employment, and decreases caregiving costs [3]. But access to care has been partly limited by the workforce shortage in child and adolescent psychiatry (CAP). We describe some possible solutions to this workforce shortage including introducing innovative shortened training pathways and tapping global trends in CAP training that efficiently address population needs.

About 8300 physicians practice CAP in the US [4]; their distribution is skewed. Massachusetts has as many child and adolescent psychiatrists as Oklahoma, Indiana, Georgia, Mississippi, and Tennessee combined, though 5 times as

Deepika Shaligram

deepika.shaligram@childrens.harvard.edu

1 Boston Children's Hospital/Harvard Medical School, Boston, MA, USA

2 Philadelphia College of Medicine, Philadelphia, PA, USA

3 Cambridge Health Alliance/Harvard Medical School, Cambridge, MA, USA

4 University of Hawaii, Honolulu, HI, USA

5 Alpert Medical School of Brown University, Providence, RI, USA

6 American Psychiatric Association Foundation, Washington, DC, USA

7 Institute of Mental Health, Singapore, Singapore

8 University of Melbourne, Melbourne, Australia

9 Cambridgeshire and Peterborough NHS Foundation Trust, Cambridge, UK

10 Norwegian University of Science and Technology, Trondheim, Norway many children live in these states [5]. A bottleneck in the workforce pipeline exists; only $10-20 \%$ of psychiatry residents choose CAP as a subspecialty. Despite efforts to increase recruitment, only $60 \%$ of CAP training spots fill although nearly all general psychiatry residency spots have filled for the last several years [6]. In 2020, there were 140 CAP training programs in the US with a total of 911 trainees inclusive of both fellowship years. Other contributory factors to workforce shortage include low financial compensation compared to other specialties, longer duration of training resulting in burgeoning trainee debt, perceived "lower" professional status, and stigma [7].

Introducing CAP earlier in medical training, and for undergraduate and school students, has been proposed as an upstream measure to increase interest and recruitment [8]. Some key initiatives to address workforce shortage include loan forgiveness programs, increasing the number of training positions, efforts to enforce parity in compensation, and innovative healthcare delivery systems (e.g., telehealth, integrated care) and decreasing training duration ("fast tracking") while retaining essential training components [9].

\section{Role of Child and Adolescent Psychiatrists in the US}

Child and adolescent psychiatrists treat children in the context of their families, schools, and communities using a biopsychosocial approach in various care settings (outpatient, inpatient, residential, day treatment, managed care, or government organizations). They also serve as educators, researchers, policy developers, and advocates for mental health. Child and adolescent psychiatrists play a consultant role in schools, hospitals, courts, state agencies, and related healthcare entities (e.g., pediatrics, social service, foster care). These settings benefit from their consultative skills in quality review, oversight of health plans, administrative and clinical leadership, design of intervention programs including niche areas (e.g., custody evaluations, neurodevelopment, addiction), and for public 
agencies [10]. While knowledge of the distribution of child and adolescent psychiatrists across specific work settings would inform training considerations in the US, this data is limited. Amongst American Academy of Child and Adolescent Psychiatry (AACAP) members who report this information, $53 \%$ work in solo private practice, $10 \%$ in academia, $12 \%$ in community settings, $4 \%$ in groups or managed care, and $21 \%$ in other settings (AACAP membership data, 2021).

\section{Current US Training}

The first CAP licensing examination was administered in 1959 [11]. CAP training in the US currently requires 4 years of medical school, at least 3 years of residency training in medicine, neurology, and general psychiatry, and 2 years of specialized training with children, adolescents, and their families in an accredited program. General psychiatry training focuses on competence in the fundamentals of the theory and practice of psychiatry. CAP training expands on general psychiatry training and emphasizes developmental and systemic factors, the diagnosis and treatment of childhood onset mental illness, and consultation to other professionals including physicians, schools, and community agencies.

The current Accreditation Council for Graduate Medical Education (ACGME) core competencies for CAP training in the US are those of all medical specialties: patient care, medical knowledge, professionalism, system-based practice, practice-based learning and improvement, and interpersonal and communication skills [12]. The knowledge, skills, attitudes, and other "milestones" for each of the ACGME competencies are organized in a developmental framework to measure performance from entry into fellowship through graduation. The Patient Care and Medical Knowledge core competencies are divided into CAP-specific sub-competencies and milestones. The other four core competencies have been "harmonized" to align across medical specialties. On completion of training, the trainee is eligible for a subspecialty certification examination in CAP through the American Board of Psychiatry and Neurology (ABPN) [13].

\section{Alternative Training Pathways to Address Workforce Shortage in the US}

There have been several initiatives to improve access to pediatric mental healthcare including the Task Force on the Crisis in Recruitment created by AACAP in 2018. This group is exploring CAP training directly from medical school in a shortened pathway as one solution to address the workforce shortage and increase recruitment of medical students into
CAP. Three specific models of a shortened pathway into CAP training were developed.

A 3-year CAP training model would confer eligibility for board certification only in CAP. It is modeled after 3year training programs in internal medicine, emergency medicine, family medicine, and pediatrics [14]. A 4-year combined psychiatry/CAP model of training directly after medical school would confer board eligibility in both general and CAP. This pathway is modeled after the ABPNapproved rotations in the Post-Pediatric Portal Programs (PPP) and Triple Board Programs [15]. Increased interest and rationale for the proposed 4-year combined training program was reflected in surveys of training faculty through AACAP, American Association of Directors of Psychiatric Residency Training (AADPRT) and American Association of Directors of Child and Adolescent Psychiatry and medical students (data presented at American Psychiatric Association (APA) Annual Meeting in 2021). This 4-year model emphasized that pediatric training in CAP would create developmentally informed experts with experience in working with families and facilitate the creation of post-residency research and subspecialty tracks in autism spectrum disorder and intellectual disability. Another proposed pathway into CAP postfamily medicine residency is modeled after the PPP and the Triple Board Program in pediatrics, general psychiatry, and CAP [11].

The AACAP Taskforce on the Crisis in Recruitment is pursuing a pilot program of the 4-year model of training directly from medical school. The proposal, which is in process, will be initiated through the ACGME-Advancing Innovation in Residency Education program and needs support from key educational stakeholders in psychiatry, i.e., AADPRT, ACGME, ABPN, and APA. Once accepted, this pilot will be closely monitored and assessed over several years to determine whether this model of training should become the default pathway into CAP.

An accelerated timeline for CAP training may require increased efficiency at two stages: undergraduate medical education (UME) and graduate medical education (GME). For example, the accelerated psychiatry program at Penn State eliminates some elective rotations at the undergraduate level to prioritize brain content in the basic science curriculum, creating an abbreviated 3-year medical school program; these students need to pursue a psychiatry residency for a time savings of at least 1 year [16].

\section{CAP Training Models Outside US}

Globally, CAP training programs emphasize the principles of development and family systems. Senior experts provide supervision and training in psychopharmacology and 
psychosocial interventions and teach didactic sessions. CAP training in many countries is fundamentally an apprenticeship within clinical services. The balance between service and training varies based on funding. In most European Union (EU) countries and the US, CAP training is federally funded. But in $10 \%$ of EU countries and in Argentina, trainees or hospitals bear the cost $[17,18]$.

Benchmarking against international training models offers innovative training opportunities that may improve access to care in the US. For instance, the CAP section of the Union of European Medical Specialists (UEMS-CAP) promotes harmonization between CAP training programs in Europe and could serve as a model for broader global collaboration [17]. One US initiative, the AACAP International, has facilitated sharing of clinical and educational resources, communication between international CAP organizations, and trainee participation in international events [19].

Global differences in CAP training are found in (1) duration of training; (2) duration of inpatient experience; (3) assessment of trainees; (4) neurodevelopmental disorders; (5) academic and research opportunities; (6) psychotherapy; (7) transitional age youth; and (8) infant and perinatal psychiatry (Table 1).

\section{Duration of Training and Inpatient Experience}

Although the required duration of CAP inpatient training in the US averages 4-6 months, the 2-year Thai CAP training has only 3 months of inpatient CAP experience. Since US psychiatry residents have had two more years of training than many overseas counterparts (who typically complete a combined 6-year UME/GME program), there is potential to decrease the overall duration of CAP training. Shifting training emphasis from inpatient to community treatment may enable a shortened duration of inpatient CAP training and thereby the overall duration of CAP training while retaining the integrity of the experience.

\section{Assessment of Trainees}

Similar to the US, Brazil, Chile, and Uruguay confer the title of CAP specialist after completing the training program; a certification exam held by the country's psychiatric association is optional [18]. In India, board certification is mandatory whereas in Singapore, Australia, and New Zealand CAP there are no specific CAP exit examinations (although trainees take rigorous general psychiatry examinations). The international variability in the requirements for a certification exam suggests that optimal assessment of CAP skills is yet to be defined, thus presenting another area for innovation and potential shortening of the training-to-practice pipeline.

\section{Academic and Research Opportunities}

Teaching and research opportunities within CAP training vary around the world. In Sweden and Germany as in the US, CAP training is centered around training in a university department thereby offering access to academic environments and immersion experiences in translational research. Nurturing academic and research opportunities is essential to prepare future generations of CAP innovators, educators, and policy makers.

\section{Psychotherapy}

In Australia, India, and New Zealand, CAP training mandates psychotherapy training with children and families using various psychotherapy models [20,21], whereas a choice between psychodynamic or cognitive behavioral tracks exists in Singapore [22]. In contrast, few European countries meet all the UEMS recommendations around duration, models, and required competencies for psychotherapy. Psychotherapy training is a substantial part of German and Swiss CAP training and the UK CAP training has mapped psychotherapy competencies for trainees [23, 24]. Currently, there is considerable variability within US programs and internationally. Strengthening CAP psychotherapy training may provide avenues for developing core skills in cultural humility and trauma-informed care.

\section{Transitional Age Youth}

Australia, Singapore, and UEMS-CAP have well-developed transitional-age youth training in CAP unlike the US. Experience with transitional age youth for CAP trainees that draws on developmental approaches has the potential to address the current silos between CAP and adult services in the US.

\section{Infant Mental Health}

Only a few US training programs (e.g., Children's Hospital of Philadelphia) offer this experience, in contrast to Australia and New Zealand where infant psychiatry is an entrustable professional activity and psychotherapy experience with children under 6 years is robust [20]. Training in the recognition and treatment of mental health problems in children $0-5$ years, the unique individual and family developmental processes of the perinatal period and early parenting align infant (and perinatal) psychiatry well with CAP training. This alignment offers unparalleled opportunities for mental health promotion, prevention of mental illness, and early intervention. 


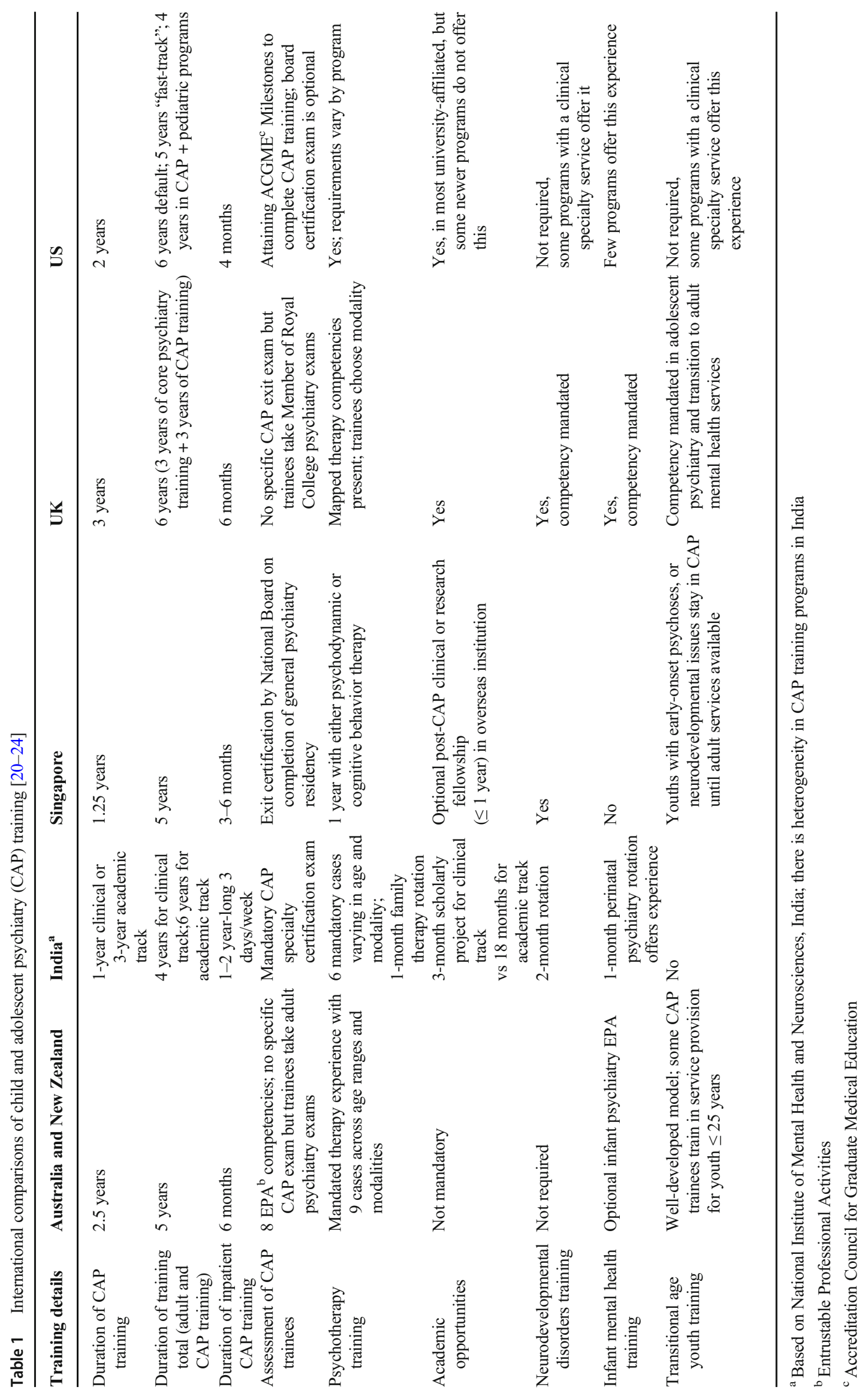




\section{CAP Training in the Twenty-First Century}

With recent strides in genetics, brain imaging, and therapeutic modalities, all informed by the social determinants of health, CAP is anticipated to grow in four areas: (1) collaborative care (CC), (2) population-based care, (3) integration of virtual, digital application-based psychotherapies and short-term interventions (1-4 sessions of psychotherapy), and (4) disaster psychiatry. While considering these growth areas and the need to optimize the duration of training, we need to adapt critical elements of existing CAP training to new competency requirements; future training needs to be different, not longer. Trainees need opportunities for practice of (1) telehealth and virtual and in-person team-based CC as a primary and/or secondary consultant, supervision, and communicating with other professionals; (2) understanding public health, population health, health policy, advocacy, and working within different systems of care; (3) teaching, training, supervision, and mentoring; and (4) systemic discrimination, cultural humility, prevention, early intervention, and trauma-informed care [25].

CAP training should consider incorporating and expanding educational research in adult learning, for interested residents, to enhance program evaluation and allow for meaningful trainee involvement in program decision-making, curriculum development, and involvement in ACGME and ABPN. In the US, trainees have hitherto been involved in the Program Evaluation Committee of every fellowship program and in the revision of ACGME Milestones. The European Federation of Psychiatric Trainees (EFPT), a group of national psychiatric trainee associations, exemplifies how trainees can organize to influence their training regulations. The EFPT works closely with UEMS-CAP to update the European CAP Training Curriculum Framework by trainee representatives joining working groups and providing feedback [22]. The EFPT also archives and annually updates records of psychiatry training including CAP in member countries, which map the evolution of CAP training across Europe and provide data to guide its representative activities. The UEMS-CAP is working with the EFPT to formalize a European Board Examination for CAP. The EFPT structure and interface with UEMS has strengths in its coordinated curriculum design and review and may serve as a model for the involvement of US trainees in committees such as ABPN and ACGME. CAP training should also increase the involvement of consumers, caregivers/parents, and others with lived experience. Further, technological advances in education (e.g., videoconferencing) could be utilized to create national and international teaching and learning collaborative networks.

The 2017 AACAP Presidential Initiative on Integrated Care underscores $\mathrm{CC}$ models as a means to improve access to care. CC models use an integrated behavioral health consultation model; the CAP consultant housed within the pediatric primary care home supports primary care providers in addressing mental health needs via in-depth consultation by CAPs. About a third of US CAP training programs offer didactic teaching and/or clinical exposure to integrated care models; trainees gain experience functioning as a consultant to multidisciplinary professionals to hone communication, consulting, and system analysis skills [26]. Optimizing the duration of traditional pediatric-inpatient-based consultationliaison model [27] could carve out time for learning skills in CC consultation with schools, pediatricians' offices, and community agencies. Australia, EU, and New Zealand are pivoting to train CAPs in (1) for direct clinical and secondary consultation to other professionals in a stepped care system, (2) clinical leadership in some specialist services, (3) balancing patient-centered care with population-based care including the sharing of resources, and (4) training and mentorship to improve the capacity of other professionals, and healthcare system management skills. Associated competencies are being delineated, for instance, training in specific consultation skills (e.g., written and summary skills for other professionals), the ability to review treatments, training and supervising others, and leadership in clinical systems.

Current US funding models limit implementation of CC curricula in CAP training. The expectation that fellows provide revenue-generating service at sponsoring institutions, difficulty getting faculty supervision at community agencies, and the reluctance of community agencies to make a "visiting" trainee a team leader presents obstacles to utilization of these sites for training [26]. Rethinking funding mechanisms and service system design allows flexibility regarding trainee placement to achieve necessary experience, ensures adequate supervision, and provides leadership opportunities for trainees in the broader consultative role. For example, in Australia, recent mental health reform and expansion allow for novel training settings for youth mental health and enable a greater experience in CC for CAP trainees. These shifts in policy, funding, and service system design are bolstered by specific training initiatives with separate funding streams, to enable training in non-traditional settings outside hospitals.

The COVID-19 pandemic has compelled the fusion of telehealth and CC to address increasing need especially in minority youth. During the pandemic, more CAP training programs used telepsychiatry (compared to approximately $60 \%$ prepandemic), teletherapy, app-based therapies, short-term interventions, and CC [28]. Innovative web-based transdiagnostic therapies are both feasible and acceptable in youth [29]. Trainees can also provide valuable input for their own training as they likely receive their own healthcare via telehealth and may have lived experiences as minorities. Formal training in telepsychiatry, teletherapy, $\mathrm{CC}$, and diversity-equity-inclusion (DEI) that teaches basic clinical skills and ethical and legal issues in these modalities is critical to modern CAP training $[27,30]$. DEI can be integrated into the curriculum longitudinally as an underlying principle of clinical learning starting 
with UME without increasing the length of training. Telehealth and $\mathrm{CC}$ can be built into existing consult-liaison and outpatient rotations such that a part of the rotation uses telehealth and outcomes/measurement-based care. Telehealthenhanced curricula can facilitate teaching infant-toddler development via remote access to nurseries, preschools, Head Start, etc.

Recent disasters both natural (e.g., the pandemic) and manmade (e.g., climate change, migration, wars, terrorist attacks) have impacted pediatric mental health significantly. Competence in the basics of disaster psychiatry in CAP training would help address evolving public health crises. The migrant crises in Europe, the Middle East, and Africa have prompted the call to provide culturally sensitive pediatric mental healthcare to survivors of war, torture, persecution, or natural disasters. Changes in family structure caused by these events and the unique vulnerabilities of unaccompanied minors demand a contextual understanding of biopsychosociocultural issues. CAP trainees need to learn essential culturally informed childrearing practices, behavior expectations, communication patterns, and coping skills to avoid diagnostic pitfalls and promote engagement. CAP training in public health analysis, advocacy skills, and the skills of collaborative approaches with stakeholders help develop patientfriendly care systems and spearhead innovation in pediatric mental health and environmental justice.

In conclusion, the dual goals presented here attempt to address the workforce crisis - optimizing training by implementing various competency-based models and new pathways while preparing CAP fellows in emerging areas to meet the challenges of the 21 st century. An inevitable tension arises between improving efficiency while requiring additional content. The answer lies in creative solutions that harness national and international innovations in training, clinical service, and systems of care. Careful monitoring and assessment of new approaches will define the path ahead to ensure that CAP meets the mental health needs of children and families in the US and the world.

\section{Declarations}

\section{Ethical Considerations Not applicable.}

Disclosures Deepika Shaligram declares no potential conflicts of interest. Bettina Bernstein receives SAMHSA peer reviewer honorarium (\$3600). Sandra M. DeJong received a Faculty Innovation in Education Grant from the American Board of Psychiatry and Neurology 2019-2020 (direct payment to develop a curriculum on pediatric telepsychiatry), royalties from Elsevier for a book on e-professionalism, and support for attending meetings/travel support from American Psychiatric Association American Association of Directors of Psychiatric Training Accreditation Council for Graduate Medical Education American Academy of Child and Adolescent Psychiatry. Anthony P.S. Guerrero declares no potential conflicts of interest. Jeffrey Hunt declares no potential conflicts of interest. Mandar Jadhav receives American Psychiatric Association Foundation Fellowship Stipend Conference Registration Fee, Travel Expenses; he is on Maryland Foundation for Psychiatry Board of Directors (volunteer position) and Indo-American Psychiatric Association Extended Executive Council (non-voting position), American Psychiatric Association Fellow Member of Council on Children, Adolescents, and their Families. Say How Ong declares no potential conflicts of interest. Paul Robertson received a funded sabbatical (5 months) June-Oct 2019 by employers Eastern Health Melbourne and The University of Melbourne; he is Chair RANZCP Faculty of Child and Adolescent Psychiatry 2017-2021 (voluntary position). Asilay Seker is President, European Federation of Psychiatric Trainees (unpaid). Norbert Skokauskas declares no potential conflicts of interest.

\section{References}

1. Whitney DG, Peterson MD. US national and state-level prevalence of mental health disorders and disparities of mental health care use in children. JAMA Pediatr. 2019;173(4):389-91.

2. Bambra C, Riordan R, Ford J, Matthews F. The COVID-19 pandemic and health inequalities. J Epidemiol Community Health. 2020;74(11):964-8.

3. Knapp M, Wong G. Economics and mental health: the current scenario. World Psychiatry. 2020;19(1):3-14.

4. American Academy of Child and Adolescent Psychiatry. Workforce Issues. https://www.aacap.org/aacap/Resources_for Primary_Care/Workforce_Issues.aspx. .

5. McBain RK, Kofner A, Stein BD, Cantor JH, Vogt WB, Yu H. Growth and distribution of child psychiatrists in the United States: 2007-2016. Pediatrics. 2019;144(6):e20191576.

6. Balon R, Morreale MK, Coverdale J, Guerrero APS, Aggarwal R, Louie AK, Beresin EV, Brenner AM. Medical students who do not match to psychiatry: what should they do, and what should we do? Acad Psychiatry. 2020;44(5):519-22.

7. Skokauskas N, Fung D, Flaherty LT, von Klitzing K, Pūras D, Servili C, Dua T, Falissard B, Vostanis P, Moyano MB, Feldman I, Clark C, Boričević V, Patton G, Leventhal B, Guerrero A. Shaping the future of child and adolescent psychiatry. Child Adolesc Psychiatry Ment Health. 2019;13:19. https://doi.org/10. 1186/s13034-019-0279-y.

8. Guerrero APS, Roberts LW. Snapshots from the cutting edge: innovations in child and adolescent psychiatry training to address workforce shortages. Acad Psychiatry. 2017;41(5):571-3.

9. Fortney JC, Pyne JM, Turner EE, Farris KM, Normoyle TM, Avery MD, Hilty DM, Unützer J. Telepsychiatry integration of mental health services into rural primary care settings. Int Rev Psychiatry. 2015;27(6):525-39.

10. Zachik AA, Naylor MW, Klaehn RL. Child and adolescent psychiatry leadership in public mental health, child welfare, and developmental disabilities agencies. Child Adolesc Psychiatr Clin N Am. 2010;19(1):47-61.

11. Sexson SB. Overview of training in the twenty-first century. Child Adolesc Psychiatr Clin N Am. 2007;16(1):1-16, vii. https://doi.org/ 10.1016/j.chc.2006.07.008.

12. Accreditation Council for Graduate Medical Education, American Board of Psychiatry and Neurology. The Child and Adolescent Psychiatry Milestones Project. http://www.acgme.org/portals/0/ pdfs/milestones/childandadolescentpsychiatrymilestones.pdf. .

13. Hunt J, Reichenberg J, Lewis AL, Jacobson S. Child and adolescent psychiatry training in the USA: current pathways. Eur Child Adolesc Psychiatry. 2020;29(1):63-9. 
14. Findling RL, Stepanova E. The workforce shortage of child and adolescent psychiatrists: is it time for a different approach? J Am Acad Child Adolesc Psychiatry. 2018;57(5):300-1.

15. Harris JC. Meeting the workforce shortage: toward 4-year board certification in child and adolescent psychiatry. J Am Acad Child Adolesc Psychiatry. 2018;57(10):722-4.

16. Psychiatry 3+ accelerated pathway - Penn State College of Medicine. Psu.edu. https://med.psu.edu/md/accelerated/psychiatry.

17. Mian AI, Milavić G, Skokauskas N. Child and adolescent psychiatry training: a global perspective. Child Adolesc Psychiatr Clin N Am. 2015;24(4):699-714.

18. Scivoletto S, Fondello MA, Otoch LN, Celeri EHRV, Caetano SC, Graeff-Martins AS, Rosario MC, Pallia R, Gutiérrez A, Valdivia M, Viola L, Polanczyk GV. Child and adolescent psychiatry training in Brazil, Argentina, Uruguay and Chile: current panorama and future challenges. Eur Child Adolesc Psychiatry. 2020;29(1):71-81.

19. American Academy of Child and Adolescent Psychiatry. AACAP International - partnering for the world's children. http://www. aacap.org/AACAP/International/Intnl_Home.aspx. .

20. Rao P, Caunt JN, Wong JWY, Moore JK, Zepf FD. Child and adolescent psychiatry training in Australia and New Zealand. Eur Child Adolesc Psychiatry. 2020;29(1):95-103.

21. Kommu JVS, Jacob P. Specialty training in child and adolescent psychiatry in India. Eur Child Adolesc Psychiatry. 2020;29(1):8993.

22. Lim CG, Ong SH, Chin CH, Fung DSS. Child and adolescent psychiatry services in Singapore. Child Adolesc Psychiatry Ment Health. 2015;9(1):7.

23. Barrett E, Jacobs B, Klasen H, Herguner S, Agnafors S, Banjac V, Bezborodovs N, Cini E, Hamann C, Huscsava MM, Kostadinova M, Kramar Y, Maravic VM, McGrath J, Molteni S, MoronNozaleda MG, Mudra S, Nikolova G, Vorkas KP, et al. The child and adolescent psychiatry: study of training in Europe (CAPSTATE). Eur Child Adolesc Psychiatry. 2020;29(1):11-27.

24. Milestone Consortium, Russet F, Humbertclaude V, Dieleman G, Dodig-Ćurković K, Hendrickx G, Kovač V, et al. Training of adult psychiatrists and child and adolescent psychiatrists in Europe: a systematic review of training characteristics and transition from child/adolescent to adult mental health services. BMC Med Educ. 2019;19(1):204.

25. Deschamps $\mathrm{P}$, Jacobs B. An international perspective on training in child and adolescent psychiatry. Eur Child Adolesc Psychiatry. 2020;29(1):1-2.

26. Burkey MD, Kaye DL, Frosch E. Training in integrated mental health-primary care models: a national survey of child psychiatry program directors. Acad Psychiatry. 2014;38(4):485-8.

27. Zimbrean PC, Ernst CL, Forray A, Beach SR, Lavakumar M, Siegel AM, Soeprono T, Schwartz AC. The educational value of outpatient consultation-liaison rotations: a white paper from the Academy of Consultation-Liaison Psychiatry residency education subcommittee. Psychosomatics. 2020;61(5):436-49.

28. Khan S, Myers K, Busch B, Brooks D, Alicata D, Ramtekkar U, Vo LC, DeJong SM. A national pediatric telepsychiatry curriculum for graduate medical education and continuing medical education. J Child Adolesc Psychopharmacol. 2021;31(7):457-63.

29. Wade SL, Gies LM, Fisher AP, Moscato EL, Adlam AR, Bardoni A, Corti C, Limond J, Modi AC, Williams T. Telepsychotherapy with children and families: lessons gleaned from two decades of translational research. J Psychother Integr. 2020;30(2):332-47.

30. Cama SF, Sehgal P. Racial and ethnic considerations across child and adolescent development. Acad Psychiatry. 2021;45(1):106-9.

Publisher's Note Springer Nature remains neutral with regard to jurisdictional claims in published maps and institutional affiliations. 